\title{
Politicians Appear more Competent when Using Numerical Rhetoric
}

\author{
Pedersen, Rasmus T.
}

\author{
Document Version \\ Accepted author manuscript \\ Published in: \\ Journal of Experimental Political Science
}

DOI:

10.1017/XPS.2017.7

Publication date:

2017

License

Unspecified

Citation for published version (APA):

Pedersen, R. T. (2017). Politicians Appear more Competent when Using Numerical Rhetoric. Journal of Experimental Political Science, 4(2), 129-150. https://doi.org/10.1017/XPS.2017.7

Link to publication in CBS Research Portal

\section{General rights}

Copyright and moral rights for the publications made accessible in the public portal are retained by the authors and/or other copyright owners and it is a condition of accessing publications that users recognise and abide by the legal requirements associated with these rights.

\section{Take down policy}

If you believe that this document breaches copyright please contact us (research.lib@cbs.dk) providing details, and we will remove access to the work immediately and investigate your claim.

Download date: 26. Apr. 2023 


\section{Politicians Appear more Competent when Using Numerical Rhetoric}

\section{Rasmus Tue Pedersen}

Journal article (Accepted manuscript)

CITE: Pedersen, R. T. (2017). Politicians Appear more Competent when Using Numerical Rhetoric. Journal of Experimental Political Science, 4(2), 129-150.

DOI: 10.1017/XPS.2017.7.

This article has been published in a revised form in Journal of Experimental Political Science http://dx.doi.org/10.1017/XPS.2017.7.

This version is free to view and download for private research and study only. Not for re-distribution, re-sale or use in derivative works. (C) The Experimental Research Section of the American Political Science Association २०17.

Uploaded to Research@CBS: December २०18 


\title{
Politicians Appear More Competent When Using Numerical Rhetoric
}

\author{
Rasmus T. Pedersen, Postdoctoral Fellow \\ Copenhagen Business School, Department of Business and Politics
}

\begin{abstract}
Politically relevant numbers often have very limited effects on the policy attitudes of ordinary citizens, which makes the widespread use of numbers by politicians' somewhat puzzling. This paper argues that politicians' numerical rhetoric may function as a voter heuristic and that the use of numbers by politicians therefore has a positive impact on voters' perceptions of these politicians. A survey experiment confirms that even when numbers do little to move voters' policy positions, numbers do have the effect of making politicians appear more competent. As a consequence, numerical rhetoric can in some cases increase electoral support for a politician.
\end{abstract}

Keywords: public opinion; voting behavior; voter heuristics; candidate traits; survey experiments

Acknowledgement: This work was supported by the Danish Council for Independent Research [grant number: 12-127749] 


\section{Introduction}

Numbers are pervasive in modern politics. Politicians readily invoke numbers about GDP growth, tax rates, unemployment, war casualties, etc., which thereby typifies the fact that numbers have become, during the last two centuries, "a central feature of public discourse" (Prévost \& Beaud, 2012).

Numbers are, however, not necessarily very persuasive in politics. Studies often find that exposure to politically relevant numbers have non-significant or very limited effects on related policy attitudes (Cohen, 2003; Kuklinski, Quirk, Jerit, Schwieder, \& Rich, 2000; Lawrence \& Sides, 2014; Gaines, Kuklinski, Quirk, Peyton, \& Verkuilen, 2007, although see Gilens, 2001; Schueler, 2015; Pedersen 2016). With this in mind, politicians' use of numbers is somewhat puzzling. Does it make sense for politicians to use numbers in their rhetoric when such numbers are seemingly so ineffective in changing the public's attitudes?

Using a survey experiment, this paper shows that the use of numbers by politicians has a substantial, positive impact on the perceptions of these politicians. By using numbers in their rhetoric, politicians may not move policy attitudes, but they can positively affect voters' perceptions about their competence and thereby also affect their electoral success.

\section{The Effects of Numbers on Personality Perceptions, Policy Positions}

\section{and a Politician's Popularity}

A politician is more than past performance, political party and policy positions. A politician is also a person. As a result, when voters form impressions of political candidates, they evaluate candidates' personality traits as well as their performance, party and policies 
(Kinder, Peters, Abelson, \& Fiske, 1980). ${ }^{1}$ In this study, we focus on the two universal dimensions on which social cognition theory and research have found that we evaluate other people or groups: competence and warmth (Cuddy, Fiske, \& Glick, 2008; Fiske, Cuddy, Glick, \& Xu, 2002). The warmth dimension reflects traits related to the intentions of an individual (or group), such as friendliness and helpfulness, whereas the competence dimension captures traits related to the abilities of the individual, such as intelligence and skills (Fiske, Cuddy, \& Glick, 2007; Koch \& Obermaier, 2014). Much has been written about how voters assess the traits of politicians and how these perceptions affect voting, but relatively little has been done to determine what politicians do, or can do, to affect these perceptions (Fridkin \& Kenney, 2011).

\section{Competence and numbers}

The key proposition in this study is that when a politician uses numbers, voters will see this politician as more competent and — by extension— be more likely to vote for this politician. To understand how numbers might affect perceptions of competence, it is useful to consider the role played by numbers in politics and society in general. The language of politics has not always been full of numbers, but numbers have played a role in public discourse since as early as the 1820 s and 1830 s — a period sometimes termed the "great explosion" of numbers by historians of statistics. Today, political issues are heavily infused with numbers (Prévost \& Beaud, 2012; Porter, 1986; Desrosiéres, 1998). Crucially, this quantification of the public discourse and politics has been seen, from the start, as a development toward a more rational form of politics and debate (e.g., Prévost \& Beaud, 2012, p. 44).

\footnotetext{
${ }^{1}$ Earlier studies on leadership traits often distinguished between four or five separable dimensions (Miller, Wattenberg, \& Malanchuk, 1986; Kinder et al., 1980), whereas later studies have tended to distinguish between two or three dimensions (e.g., Funk, 1996; Koch \& Obermaier, 2014). For an overview, see Ohr and Oscarsson (2013).
} 
Given this widespread cultural perception of numbers as being closely associated with rationality and knowledge, the presence of numbers in a politician's rhetoric may be used as a cognitive shortcut (a heuristic) by voters when forming an assessment of that politician. Voters have been found to use several heuristics when assessing political candidates, for example party ID, candidate endorsements, poll standings, and facial features (Lau \& Redlawsk, 2006; Lau \& Redlawsk, 2001; Campbell \& Cowley, 2014; Utych \& Kam, 2014; Berggren, Jordahl, \& Poutvaara, 2010). This study suggests that we add a numbers-ascompetence heuristic to this list of heuristics. Based on this, we hypothesize that the use of numbers by a political actor increases the perceived competence of that actor.

\section{Warmth and Numbers}

The use of numbers could potentially also have effects on perceived warmth. However, the direction of such an effect could be in both directions. On the one hand, competence and warmth often correlate positively, and a higher assessment of competence could therefore be associated with a higher assessment of warmth through the halo effect (Fiske et al., 2007). On the other hand, there is sometimes a compensatory effect when comparing several people on different traits, such that when one person is judged more positively on one dimension, the second person is judged more positively on the other dimension. (Kervyn, Yzerbyt, \& Judd, 2010; Judd, James-Hawkins, Yzerbyt, \& Kashima, 2005). We therefore do not have any expectations regarding the effect of numerical rhetoric on perceived warmth, but, for completeness, the study also tests whether the use of numbers by a political actor increases or decreases the perceived warmth of that actor.

\section{Policy Positions and Numbers}

Given that numerical rhetoric may have an effect on perceptions of personality traits, it is tempting to assume that this type of rhetoric will also be more persuasive, i.e., effective in 
changing the policy attitudes of voters on the subject being discussed. However, as previously noted, a large number of studies have shown that numbers are generally quite ineffective at achieving this; presenting people with politically relevant numbers often does little to affect their opinions regarding policies on those issues (Kuklinski et al., 2000; Lawrence \& Sides, 2014; Gaines et al., 2007). Therefore, we hypothesize that the use of numbers by a political actor will have limited and/or insignificant effects on voters' policy attitudes.

\section{Voting and Numbers}

If the use of numbers does lead voters to see a politician as more competent, this can have electoral consequences. Several studies have shown that trait perceptions are associated with voters' overall evaluation of candidates and, in some cases, vote choice (Hayes, 2010; Fridkin \& Kenney, 2011; Funk, 1999; Miller et al., 1986; Bartels, 2002). Furthermore, studies focusing specifically on the role of competence have found that perceptions of this trait do affect overall assessments and voting intentions (Koch \& Obermaier, 2014; Funk, 1996). Assessments of a candidate's competence are obviously not the only factor affecting a voter's propensity to vote for that candidate, and using vote choice as a dependent variable is therefore a very stringent test of numerical rhetoric's effect. Nevertheless, we hypothesize that the use of numbers by a political actor increases the propensity of voters to vote for that politician. Furthermore, we expect that this effect of numerical rhetoric is mediated by perceived competence. 


\section{Methods}

The experiment was conducted in a commercial web panel (Epinion). ${ }^{2}$ Members of the panel were invited by email to participate, and out of the 1,294 respondents who started the survey, $79 \%$ completed the entire survey. More importantly, the drop-off after exposure to the experimental stimuli did not differ significantly across experimental conditions, $\chi^{2}(3$, $\mathrm{N}=1,210)=0.61, \mathrm{p}=.89$. The sample exhibited substantial variation in demographic and attitudinal variables: $52 \%$ of the sample was female, the ages ranged from 18 to $79(M=49$, $\mathrm{SD}=16$ ), and $47 \%$ had completed tertiary-level education (college level). Furthermore, the sample represented the full left-right political spectrum $(\mathrm{M}=.49, \mathrm{SD}=.27$, scale range: $0-1)$.

Stimuli: Respondents were instructed to read a brief discussion between two fictitious politicians on the issue of genetically modified foods ("GM foods"). Respondents were randomly assigned to one of four conditions (randomization was undertaken by the survey company). In Condition 1 (baseline condition) both politicians argued without using any numbers, one in favor of GM foods and one against. In Condition 2, the argument made by the politician against GM foods remained exactly the same, whereas the arguments made by the politician in favor of GM foods were quantified. Instead of arguing, for example, that "GM foods markedly reduce the use of pesticides," the politician now stated that "GM foods reduce the use of pesticides by 50\%." In Condition 3, this was reversed so that the politician arguing against GM foods was now using numbers, whereas the politician in favor did not use any numbers. Finally, in Condition 4, both politicians used numbers. ${ }^{3}$ Because the only variation was the quantification of the statements, the texts in all four conditions were of

\footnotetext{
${ }^{2}$ www.epinionglobal.com (The survey was fielded between 22 May and 14 June 2015).

${ }^{3}$ To avoid any ordering effects, the order of the discussion (pro versus con) was also randomized.
} 
almost identical length (135-139 words in original language. See the full text in replication materials).

The issue of GM foods is a relatively unsettled political issue, and while parties on the left side of the political spectrum tend to be more skeptical of GM foods than parties on the right, the policy positions on this issue do not implicitly provide respondents with clear party cues. In contrast, positions on many economic issues would most likely be completely crystalized and, at the same time, provide respondents with implicit party cues, thereby minimizing the likelihood of the respondent being affected by the arguments (for a similar line of reasoning, see Druckman, Peterson, \& Slothuus, 2013). ${ }^{4}$ As a result, choosing this issue maximized the chance that the discussion might actually change the respondents' policy positions, not just their perceptions of the politicians. As a relatively technical political issue, a political debate on GM foods may lend itself particularly well to quantification, and we will return to the issue of generalizability across policy issues in the concluding discussion.

The experiment used a stimulus with two politicians for two reasons. First, while experiments on communication effects have often used one-sided stimuli where the respondents are restricted to hearing just one position on a political issues, the most typical information environment for citizens is an environment in which alternative interpretations of a political issue are presented (Sniderman \& Theriault, 2004; Chong \& Druckman, 2007). Second, people are inclined to evaluate other people in a comparative rather than an absolute manner (Goffin \& Olson, 2011). By asking respondents to rate the traits of two politicians rather than just one, we can arrive at more precise estimates of the effects of numerical rhetoric.

\footnotetext{
${ }^{4}$ Similar to Campbell \& Cowley (2015) we therefore also avoid party labels in the experiment.
} 
Dependent variables: After reading the discussion, respondents were asked to evaluate the two politicians on four traits associated with competence (Intelligent, competent, credible, knowledgeable), and four traits associated with warmth (Likeable, conscientious, friendly, caring). ${ }^{5}$ These items formed reliable scales for both competence (Cronbach's $\alpha=0.88-0.90$ ) and warmth $(\alpha=0.83-0.85) .{ }^{6}$ Scales for competence and warmth were standardized to range from zero to one. Scales for the differences in perceptions between the two politicians were simply constructed by subtracting the assessment of the "con" politician from the assessment of the "pro" politician; these scales consequently ranged from -1 to 1 for both traits. Finally, respondents were asked about which politician they would vote for, their personal opinion about GM foods and two questions about their recall of the use of numbers in the discussion (see replication materials for exact question wordings).

\section{Findings}

Effects on trait perceptions: An ANOVA test with differences in competence assessments as the dependent variable, shows highly significant effects for the experimental treatment $(\mathrm{F}(3,920)=10.72, \mathrm{p}<.001)$. Figure 1 shows the mean assessments of the two politicians sorted by experimental conditions (based on Models 1 and 2 in the appendix). In Condition 1, where none of the politicians used numbers, the two politicians are regarded as essentially similar in competence, with mean scores of 0.56 and 0.55 , respectively. In condition 2 , where the "pro" politician used numbers, this politician have a mean assessment of 0.61 , while the "con" politician have a mean assessment of just 0.51 . Here, the difference in assessments became

\footnotetext{
${ }^{5}$ These items have all previously been used in trait studies (Koch \& Obermaier, 2014; Funk, 1997; Gonzales, Kovera, Sullivan, \& Chanley, 1995; Goren, 2002; Funk, 1996; Schneider \& Bos, 2014; Fridkin \& Kenney, 2011; Funk, 1999).

${ }^{6}$ A factor analysis confirmed that these eight personality traits loaded on two separate factors. Respondents with $\geq 3$ "don't know" answers on a trait were excluded from subsequent analysis.
} 
significantly larger than in the baseline condition ( $p=.002$, based on Model 3). In Condition 3, where the "con" politician used numbers, this pattern was reversed, as expected, and the "con" politician have a higher mean assessment (0.60) than the "pro" politician (0.55). Again, the relative assessment is significantly different from the baseline in Condition $1(\mathrm{p}=.017)$.
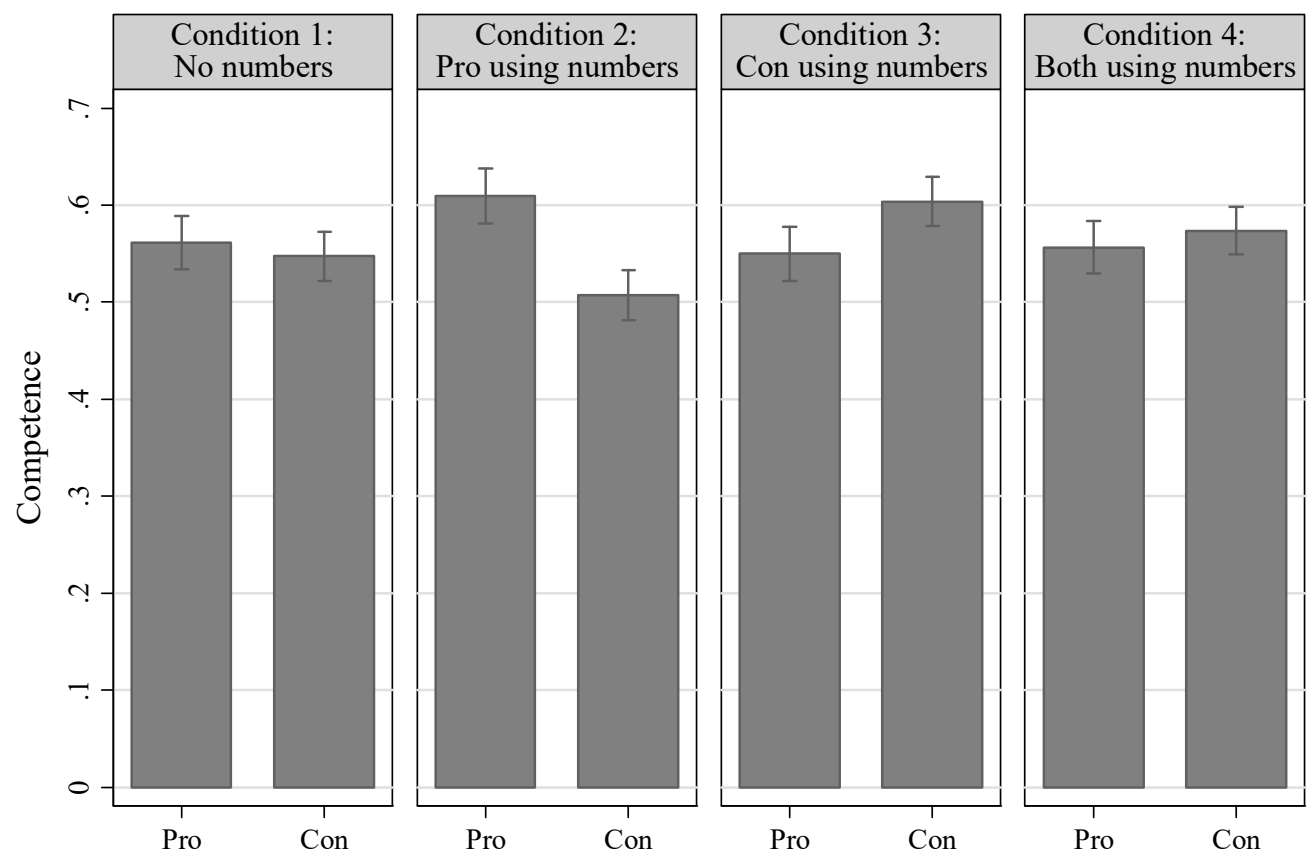

Figure 1: Mean assessments of the two politicians' competence, contingent on

experimental conditions (with 95\% CIs). Based on Models 1 and 2 in the appendix.

Finally, in Condition 4, where both politicians use numbers, we see results similar to the results in Condition 1. The two politicians are rated equally, at the same level as in Condition 1. While it may seem surprising that the assessment of competence of the two politicians is not higher than in the baseline condition, the result in condition 4 likely reflect that people tend to rate other people in a comparative rather than an absolute manner (Goffin \& Olson, 2011). A reasonable conclusion could therefore be that the use of numerical rhetoric increases a politician's relative competence, regardless of whether the opposing politician uses numbers or not. A comparison between Conditions 2 and 4 confirms that the "con" politician significantly decreased the difference by using numbers when the "pro" politician was also 
using numbers $(\mathrm{p}<.001)$. A comparison between Conditions 3 and 4 shows the same pattern, although the effect was not significant $(\mathrm{p}=.20)$. Nevertheless, in three out of the four comparisons conducted, the effect of using numbers has a clearly significant effect on the relative competence of the politicians, which suggests that the use of such numerical rhetoric may be an efficacious way of improving the electorate's perceptions of a politician.

The effect sizes may seem at first sight to be relatively limited, but it is important to note that the variance of the measure of perceived competence is relatively low. As a result, these ostensibly small differences are of some consequence: For example, when the "pro" candidate uses numbers (in Condition 2), this politician is regarded as being more competent than the "con" candidate by $45 \%$ of respondents $(95 \% \mathrm{CI}[39,52])$. However, when the "pro" candidate does not use numbers and the "con" candidate does (Condition 3 ), the share of respondents judging the "pro" candidate to be more competent than the "con" candidate drops to just $28 \%(95 \% \mathrm{CI}[23,35])$.

As a next step in the analysis, we ask if the positive effect on perceptions of competence is accompanied by an effect on perceptions regarding the politicians' warmth. The results of an ANOVA-test indicate that this is not the case, as the experimental treatment has an insignificant effect overall on the differences of perceptions of warmth $F(3,920)=1.27$, $\mathrm{p}=.28$ ). Even if we disregard the insignificance of this omnibus test and look at the individual conditions in Figure 2, the result stands: The differences in the assessments of warmth do not differ significantly between any of the four conditions (all $p>.05$ based on Model 6 in the appendix). 

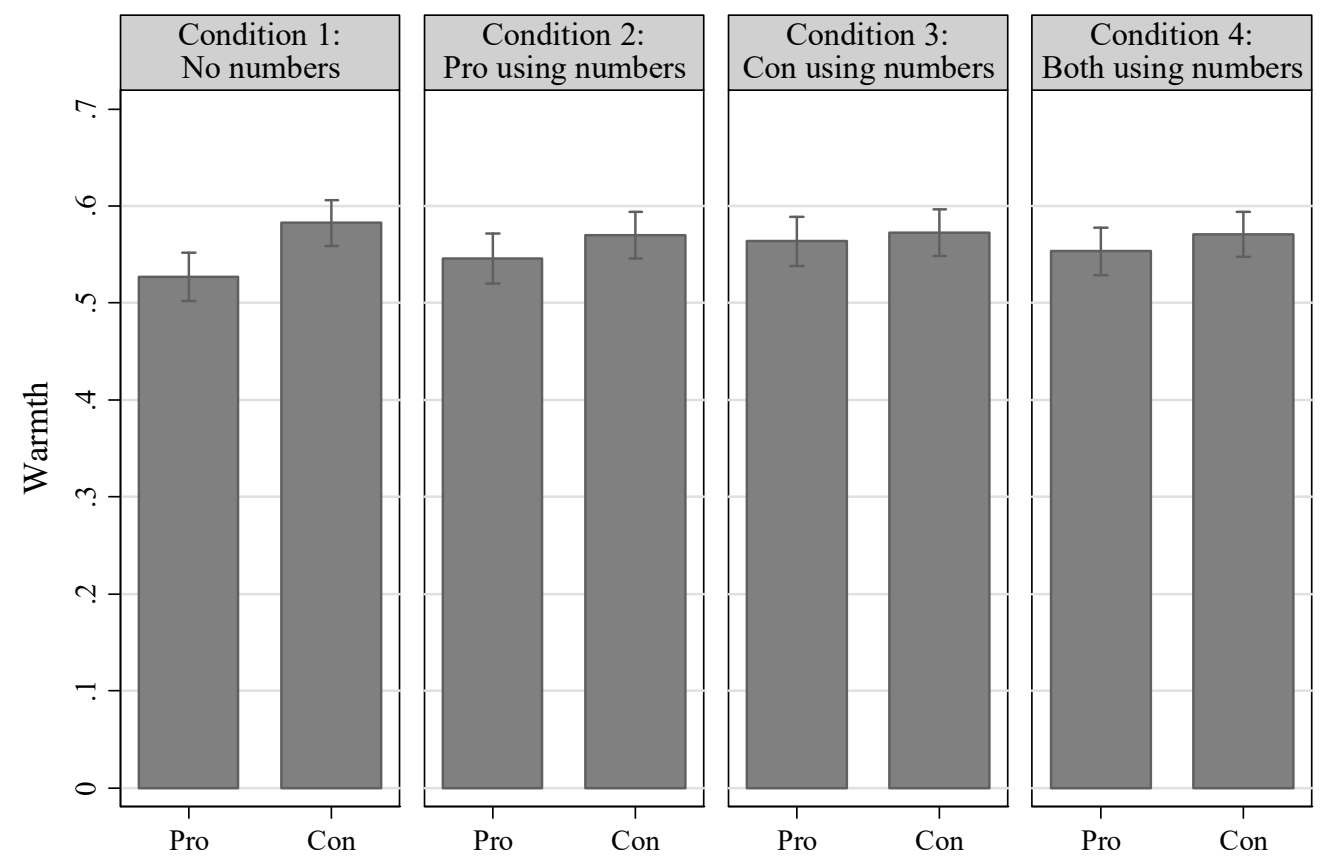

Figure 2: Mean assessments of the two politicians' warmth, contingent on the experimental condition (with 95\% CIs). Based on Models 4 and 5 in the appendix.

Effects on GM-attitudes: the results of an ANOVA test clearly show that the experimental treatment has an insignificant effect overall on attitudes regarding $\mathrm{GM}$ foods $(\mathrm{F}(3,920)=0.07$, $\mathrm{p}=0.97) .{ }^{7}$ As illustrated in Figure 3 below, the attitudes were strikingly similar across experimental conditions: slightly negative in all cases.

\footnotetext{
${ }^{7}$ This analysis places the 52 respondents answering "don't know," at the middle of the scale. Excluding these respondents does not change the conclusions
} 


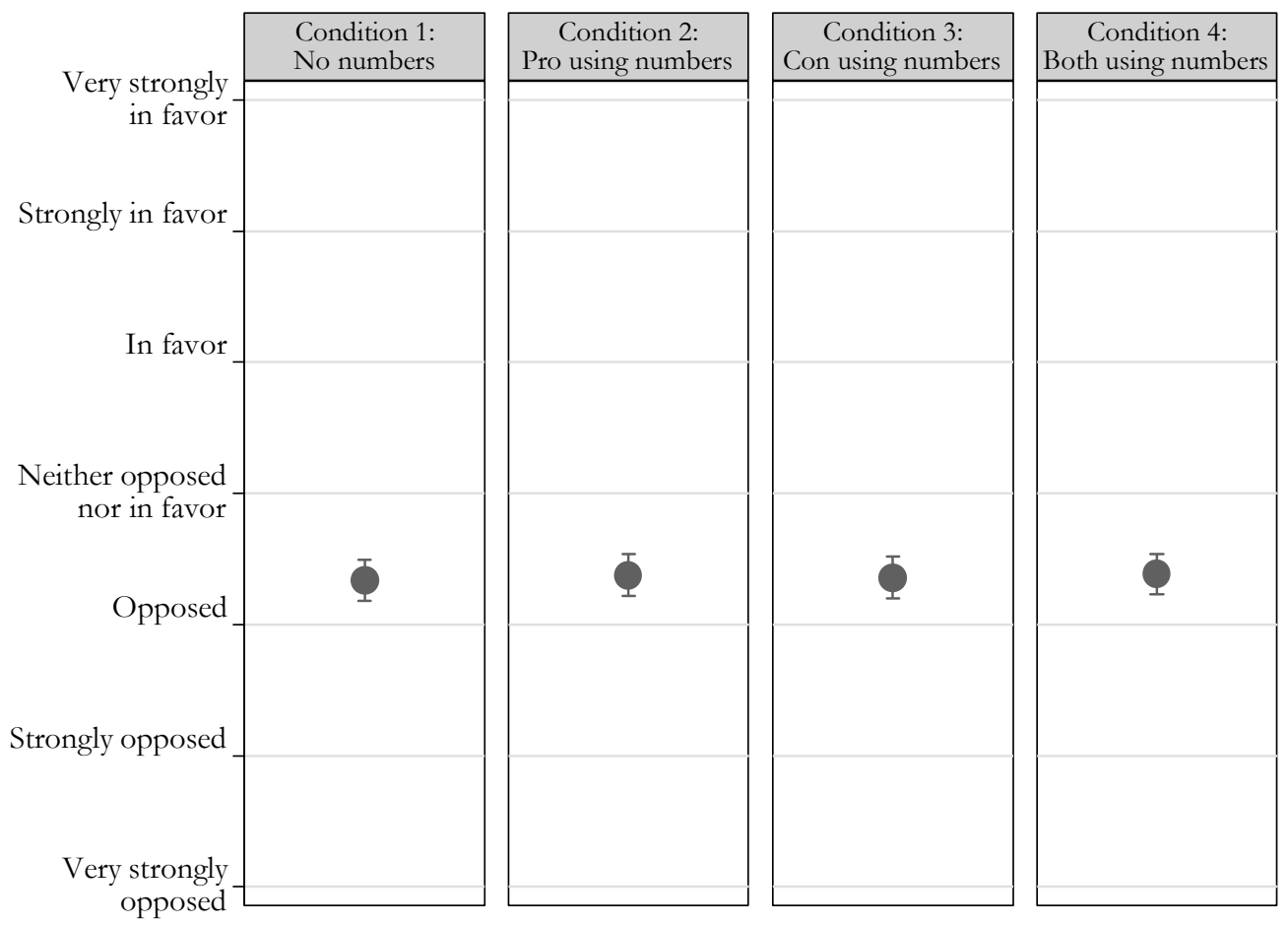

Figure 3: Mean attitudes on GM foods contingent on the experimental condition (with 95\% CIs). Based on Model 7 in the appendix.

In this regard, therefore, the experiment aligns very well with previous studies investigating the effect of numbers on policy attitudes (Lawrence \& Sides, 2014; Kuklinski et al., 2000) Numbers do not seem to have strong persuasive powers in regard to changing policy attitudes. They do, however, have marked effects on the perceived competence of politicians.

Effects on voting: Does the boost in perceived competence then translate into electoral popularity for the politician using numbers? We start by looking at the total effect. Again, an ANOVA shows significant effects of the experimental treatment on vote choice $(F(3,920)$ $=2.63, \mathrm{p}=.049) .{ }^{8}$ As illustrated in figure 4 , the pattern across conditions is also as expected: electoral support for the "pro" politician is highest in condition 2-where this politician is the

\footnotetext{
${ }^{8}$ The 231 respondents answering "don't know" are placed at the middle of the scale. Excluding these and analyzing the resulting four-point scale with an ordered logistic regression, also yield significant findings $\chi^{2}(3)=8.65, \mathrm{p}=0.034$.
} 
only one using numbers - and it is lowest in condition 3-where the "con" politician is the only one using numbers. However, the effect of numerical rhetoric does not seem to be symmetrical: support for pro is significantly higher in condition 2 than all other conditions $(p<.05)$, whereas none of the other conditions differs significantly from each other). We will revisit the question of a potential asymmetrical effect below.

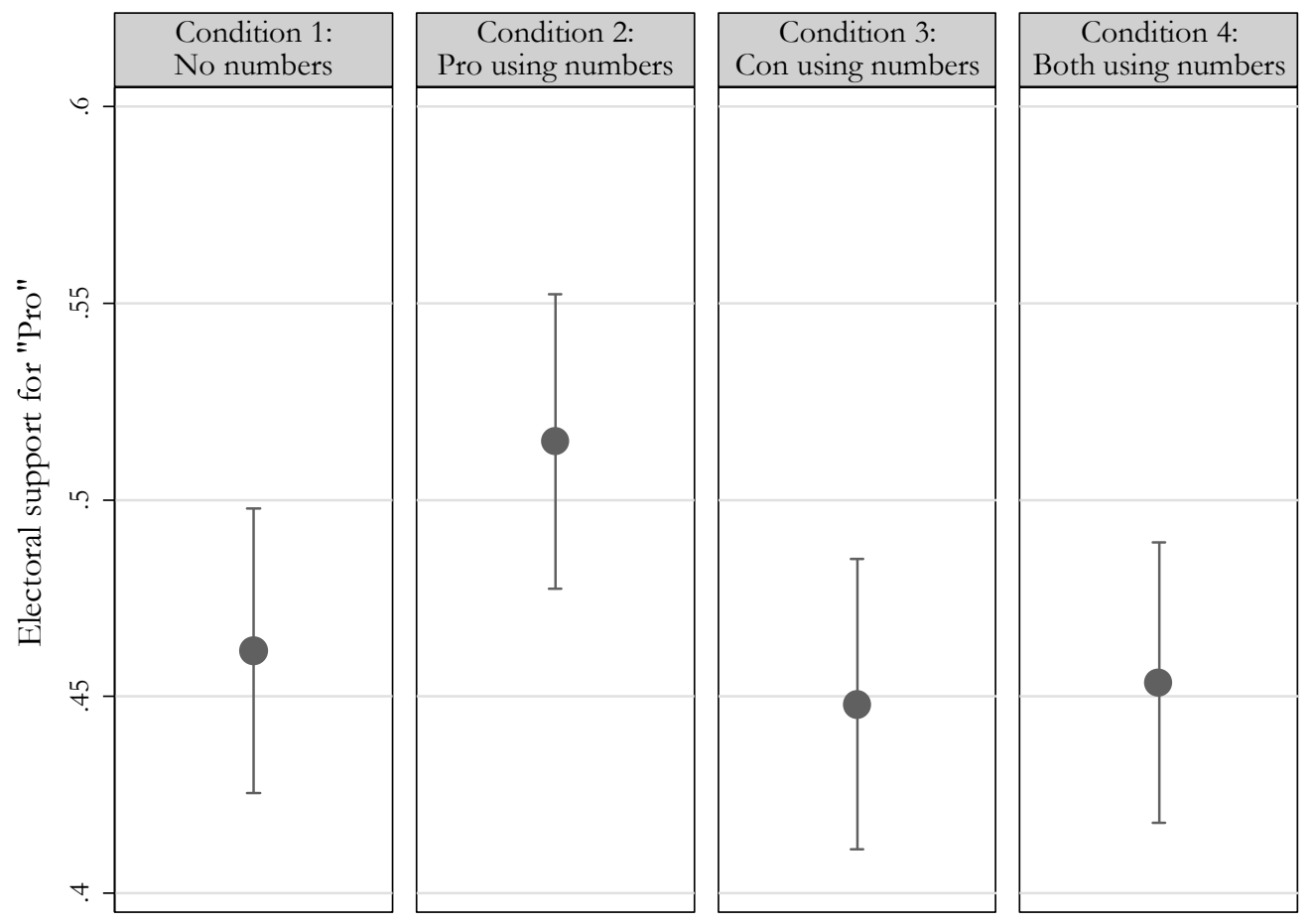

Figure 4: This figure illustrates mean electoral support for "pro" contingent on the experimental condition (with 95\% CIs). Based on Model 8 in the appendix.

To investigate whether this effect of numerical rhetoric on vote choice is in fact mediated by perceived competence, the final step in the analysis is to conduct a mediation analyses. It is important to note that, even in experimental studies such as this, the randomization of the treatment variable cannot remove the possibility of a confounding variable affecting both the mediator and the outcome variable. Hence, mediation analyses rest on the strong assumption of "sequential ignorability" (Keele, 2015; Imai, Keele, Tingley, \& Yamamoto, 2011). To 
address this challenge, the analysis therefore uses the approach developed by Imai et al. (Imai, Keele, \& Tingley, 2010a; Imai, Keele, Tingley, \& Yamamoto, 2010b; Tingley, Yamamoto, Hirose, Keele, \& Imai, 2014). In this approach, one first estimates the mediation effect and then estimates how robust this estimate of the mediation effect is to violations of sequential ignorability.

We start the mediation analysis with a comparison of conditions 2 and 3, i.e. the two conditions where either pro or con uses numbers. An estimation based on models 10 and 11 shows that perceived competence is indeed a mediator. The average causal mediation effect (ACME) of perceived competence is 0.09 points on the $0-1$ range scale of vote intention. This effect is highly significant $(\mathrm{p}<.001)$, whereas the average direct effect $(A D E)$, which encompasses all other possible causal mechanisms, is negative (-.03) and insignificant $(p=.15)$. As a result, the effect mediated by competence is actually larger than the total effect, although insignificantly so, clearly indicating that perceived competence is a key mediatorpossible the only mediator — connecting numerical rhetoric and vote choice. ${ }^{9}$ An analysis for perceived warmth as a mediator, based on models $12-13$ confirms that this variable is not a significant mediator, as ACME is only -.01 points and insignificant $(p=.45)$. Similarly the estimated mediation effect of GM-attitudes (models 14-15) is just -0.002 points and clearly insignificant $(p=.84) .^{10}$

\footnotetext{
${ }^{9}$ As noted by one of the anonymous reviewers, the impact of competence on voting may have been inflated by asking about traits immediately before soliciting respondents' vote preference. Future studies may want to investigate whether the effect of rhetorical numbers on vote choice is of the same magnitude, if respondents are not asked questions regarding competence.

${ }^{10}$ While traditional mediation analyses often include several potential mediators in the same structural equation model, such an approach does not add anything to this simpler onemechanism-at-a-time procedure (Imai \& Yamamoto, 2013, p. 150).
} 
This result is generally supported by all the other comparisons of experimental conditions: the ACMEs of competence are significant in four of the five comparisons where we would expect them to be, (there is no reason to expect an effect when comparing conditions 1 and 4), and ACME for warmth and GM-attitude remain insignificant in all comparisons. These additional models do not provide us with a clear answer as to why there is an asymmetrical effect on vote choice, as suggested by figure 4. In all the relevant comparisons, the ACME of competence is insignificantly smaller for "con" than for "pro," and the oppositely signed $\mathrm{ADE}$ (encompassing all other potential mediators) is insignificantly larger. Together, these small differences lead to the asymmetry. Hence, the asymmetry is not caused by differences in mediation through warmth or GM-attitudes (For full results, see table 6 and figure 5 in the appendix).

The subsequent sensitivity analysis shows that the significant mediation effect of perceived competence is highly robust to violations of the sequential ignorability assumption. For all of the comparisons in which the ACMEs are significant, they remain significant at a $95 \%$-level as long as the sensitivity parameter $\rho$ is below .58 (Compare, e.g., to results in Imai \& Yamamoto, 2013). For both perceived warmth and GM-attitude, ACME remains insignificant for all values of $\rho$ (Full results of sensitivity analysis in the appendix, figure 6$).{ }^{11}$

While warmth and GM-attitudes do not seem to mediate the effect of numerical rhetoric on vote choice, these two variables are not irrelevant for the respondents' vote choice. First, both variables have significant impact on vote choice (as shown in model 16). The reason that they

\footnotetext{
${ }^{11}$ In cases with several causally dependent mediators, correct estimation of ACME requires the assumption of homogenous interaction effect (Imai \& Yamamoto, 2013). The method developed by Imai et al. also allow for a sensitivity test of violations of this assumption, but since the analysis have only shown one mediator (perceived competence) and given no indication whatsoever that perceived warmth or GM-attitudes are mediators, there would be little gained from conducting such a sensitivity test.
} 
do not serve as significant mediators is simply that they are not significantly affected by the experimental treatment, which mediators, by definition, must be (Imai \& Yamamoto, 2013, p. 147).

Second, the effects of numerical rhetoric could potentially also be moderated by the respondents' GM-attitudes. ${ }^{12}$ Specifically, one could imagine that numerical rhetoric mainly has an effect among respondents without a strong policy position on GM-foods, because strong opponents of GM-foods would uniformly regard the "con" politician as more competent and vote for this politicians regardless of rhetoric. Similarly, one would expect that strong proponents of GM-foods would have a strong tendency to consider the "pro" politician as more competent and vote for this politician regardless of rhetoric.

To test this potentially moderating effect of GM-attitudes, models 17 and 18 in table 7 include the relevant interaction terms. Since one would expect the strength, rather than the valence, of the respondents' GM-attitude to moderate the effects, the measure of GMattitudes is folded, such that a value of zero denotes no position on the issue of GM-foods, whereas a value of one denotes a strong position (positive or negative) on the issue. ${ }^{13}$

When analyzed separately, models 17 and 18 reveals no significant interactions between experimental conditions and GM-attitudes, neither when it comes to predicting perceived competence (model 17), nor when it comes to predicting vote choice (model 18). ${ }^{14}$ As an additional check, we can use the two models to test for moderated mediation (Tingley et al.,

\footnotetext{
${ }^{12}$ I thank one of the anonymous reviewers for pointing this out.

${ }^{13}$ It should be noted that this inclusion of GM-attitudes in the model does entail the risk of creating post-treatment bias, because GM-attitudes were measured after the experimental treatment (Montgomery et al., 2016). However, since the data do not indicate that GMattitude is affected by the treatment, we therefore treat GM-attitude as a pretreatment covariate for the sake of this explorative analysis (c.f. Imai et al. 2014).

${ }^{14}$ Model 18 includes an interaction between perceptions of competence and GM-attitudes in order to be able to analyze mediated mediation properly (Tingley et al., 2014).
} 
2014), again focusing on conditions 2 and 3. The results of this analysis are, at first sight, suggestive of moderated mediation: the ACME of competence is $0.11(\mathrm{p}<.001)$ for respondents without a clear GM-attitude, while it is ostensibly smaller $(0.06, p=.08)$ for respondents with a strong attitude. However, this difference in effect sizes is insignificant $(p=.15)$, and when estimating the total effect (ACME + ADE), respondents with a strong attitude are affected to essentially the same degree as respondents without a strong GMattitude (the total effect is .06 points in both cases). Together these results suggest that the numbers-as-competence heuristic is not necessarily just a heuristic used by voters without a clear policy position on which to base their vote choice.

Recall of number use: One final concern might be that the effects found in this experiment are contingent on a level of attention not usually given to political communication by the ordinary voter. However, when asked at the end of the survey whether just the "pro" politician, just the "con" politician, both the politicians, or none of them had used numbers, just $62 \%$ of respondents gave the correct answer $(95 \% \mathrm{CI}[59,65])$. Furthermore, when respondents in Conditions 2-4, where one or both of the politicians had used numbers, were asked about the specific number for the increase or decrease in the use of pesticides, only $47 \%(95 \% \mathrm{CI}[43,51])$ of the respondents successfully chose the right answer among six alternatives. In other words, the respondents in this experiment were showing a level of inattention and sloppiness that may be comparable to the level found among the general electorate.

\section{Conclusion and Discussion}

The experiment reported in this manuscript is a clear example of how the use of numbers by political actors may increase their perceived competence and thereby their electoral success. Future studies may want to investigate the degree to which this effect is generalizable across 
policy issues. The issue of genetically modified foods may lend itself more easily to numerical rhetoric than other issues, although it is difficult to imagine policy issues completely devoid of potentially relevant numbers. Future studies may also want to investigate the degree to which the effects depend on the numerical formats themselves. People tend, for example, to see precise numbers as more informed and credible than round numbers (Zhang \& Schwarz, 2013), and politicians may use - sometimes exceedingly precise numbers in order to further boost their perceived competence.

As with other voter heuristics, the pressing question is whether this heuristic somehow helps voters arrive at a more informed, or in other ways qualitatively better, decision, or whether the heuristic misleads the voters (Lau \& Redlawsk, 2001; Bartels, 1996). Clearly, the fact that so many subjects in this experiment were unable to recall the numbers used - or even which politician used the numbers - may indicate that numerical rhetoric does not result in voters who are substantially more informed on policy issues. The results here also align well with many previous studies that show that people are, in general, fairly ignorant about policyrelevant numbers (Lawrence \& Sides, 2014; Kuklinski et al., 2000; Herda, 2010; Sigelman \& Niemi, 2001; Nadeau, Niemi, \& Levine, 1993; Wong, 2007). Conversely, one could argue that heuristics are useful exactly because they do not require much information and that politicians' numerical rhetoric may in fact be a democratically valuable heuristic. The successful use of numerical rhetoric by a politician does arguably require at least some level of knowledge about a given policy issue, as they are very likely to be called out on any wrong numbers. As a result, using numbers might help the electorate choose politicians that are indeed more competent.

Regardless of whether the numbers-as-competence heuristic allows "low information rationality" (Popkin, 1991) at the level of the voter, numerical rhetoric does seem to be a 
rational strategy at the level of the political candidate. Candidates' numbers may not move our policy attitudes, but they will make us perceive them as more competent. 


\section{References}

Bartels, L. M. (1996). Uninformed Votes: Information Effects in Presidential Elections. American Journal of Political Science, 40(1), 194-230.

Bartels, L. M. (2002). The Impact of Candidate Traits in American Presidential Elections. In A. King (Ed.), Leaders' Personalities and the Outcomes of Democratic Elections. New York, NY: Oxford University Press.

Berggren, N., Jordahl, H., \& Poutvaara, P. (2010). The looks of a winner: Beauty and electoral success. Journal of Public Economics, 94(1-2), 8-15. doi: http://dx.doi.org/10.1016/j.jpubeco.2009.11.002

Campbell, R., \& Cowley, P. (2014). What Voters Want: Reactions to Candidate Characteristics in a Survey Experiment. Political Studies, 62(4), 745-765. doi: $10.1111 / 1467-9248.12048$

Campbell, R., \& Cowley, P. (2015). Attitudes to Moonlighting Politicians: Evidence from the United Kingdom. Journal of Experimental Political Science, FirstView, 1-10. doi: doi:10.1017/XPS.2014.21

Chong, D., \& Druckman, J. N. (2007). Framing public opinion in competitive democracies. American Political Science Review, 101(4), 637-655.

Cohen, G. L. (2003). Party over policy: The dominating impact of group influence on political beliefs. Journal of Personality and Social Psychology, 85(5), 808-822. doi: $10.1037 / 0022-3514.85 .5 .808$

Cuddy, A. J. C., Fiske, S. T., \& Glick, P. (2008). Warmth and Competence as Universal Dimensions of Social Perception: The Stereotype Content Model and the BIAS Map. In P. Z. Mark (Ed.), Advances in Experimental Social Psychology (Vol. Volume 40, pp. 61-149): Academic Press. 
Desrosiéres, A. (1998). The Politics of Large Numbers - A History of Statistical Reasoning. Cambridge: Harvard University Press.

Druckman, J. N., Peterson, E., \& Slothuus, R. (2013). How Elite Partisan Polarization Affects Public Opinion Formation. American Political Science Review, 107(1), 57-79.

Fiske, S. T., Cuddy, A. J., Glick, P., \& Xu, J. (2002). A model of (often mixed) stereotype content: competence and warmth respectively follow from perceived status and competition. Journal of Personality and Social Psychology, 82(6), 878.

Fiske, S. T., Cuddy, A. J. C., \& Glick, P. (2007). Universal dimensions of social cognition: warmth and competence. Trends in Cognitive Sciences, 11(2), 77-83. doi: http://dx.doi.org/10.1016/j.tics.2006.11.005

Fridkin, K. L., \& Kenney, P. J. (2011). The Role of Candidate Traits in Campaigns. The Journal of Politics, 73(01), 61-73. doi: doi:10.1017/S0022381610000861

Funk, C. L. (1996). The Impact of Scandal on Candidate Evaluations: An Experimental Test of the Role of Candidate Traits. Political Behavior, 18(1), 1-24. doi: 10.2307/586509

Funk, C. L. (1997). Implications of Political Expertise in Candidate Trait Evaluations. Political Research Quarterly, 50(3), 675-697. doi: 10.2307/448922

Funk, C. L. (1999). Bringing the Candidate into Models of Candidate Evaluation. The Journal of Politics, 61(3), 700-720. doi: 10.2307/2647824

Gaines, B. J., Kuklinski, J. H., Quirk, P. J., Peyton, B., \& Verkuilen, J. (2007). Same Facts, Different Interpretations: Partisan Motivation and Opinion on Iraq. Journal of Politics, 69(4), 957-974. doi: 10.1111/j.1468-2508.2007.00601.x

Gilens, M. (2001). Political Ignorance and Collective Policy Preferences. American Political Science Review, 95(2), 379-396. 
Goffin, R. D., \& Olson, J. M. (2011). Is It All Relative?: Comparative Judgments and the Possible Improvement of Self-Ratings and Ratings of Others. Perspectives on Psychological Science, 6(1), 48-60. doi: 10.1177/1745691610393521

Gonzales, M. H., Kovera, M. B., Sullivan, J. L., \& Chanley, V. (1995). Private Reactions to Public Transgressions: Predictors of Evaluative Responses to Allegations of Political Misconduct. Personality and Social Psychology Bulletin, 21(2), 136-148. doi: $10.1177 / 0146167295212004$

Goren, P. (2002). Character Weakness, Partisan Bias, and Presidential Evaluation. American Journal of Political Science, 46(3), 627-641. doi: 10.2307/3088404

Hayes, D. (2010). Trait Voting in U.S. Senate Elections. American Politics Research, 38(6), 1102-1129. doi: $10.1177 / 1532673 \times 10371298$

Herda, D. (2010). How Many Immigrants?: Foreign-Born Population Innumeracy in Europe. Public Opinion Quarterly, 74(4), 674-695. doi: 10.1093/poq/nfq013

Imai, K., Keele, L., \& Tingley, D. (2010a). A general approach to causal mediation analysis. Psychological methods, 15(4), 309-334. doi: 10.1037/a0020761

Imai, K., Keele, L., Tingley, D., \& Yamamoto, T. (2010b). Causal mediation analysis using R. Advances in social science research using R, 196, 129-154. doi: 10.1007/978-14419-1764-5_8

Imai, K., Keele, L., Tingley, D., \& Yamamoto, T. (2011). Unpacking the black box of causality: Learning about causal mechanisms from experimental and observational studies. American Political Science Review, 105(04), 765-789. doi:10.1017/S0003055411000414

Imai, K., Keele, L., Tingley, D., \& Yamamoto, T. (2014). Comment on Pearl: Practical implications of theoretical results for causal mediation analysis. Psychological Methods, 19(4), 482- 487. 
Imai, K., \& Yamamoto, T. (2013). Identification and sensitivity analysis for multiple causal mechanisms: revisiting evidence from framing experiments. Political Analysis, 21(2), 141-171. doi:10.1093/pan/mps040

Judd, C. M., James-Hawkins, L., Yzerbyt, V., \& Kashima, Y. (2005). Fundamental dimensions of social judgment: Understanding the relations between judgments of competence and warmth. Journal of Personality and Social Psychology, 89(6), 899913. doi: $10.1037 / 0022-3514.89 .6 .899$

Keele, L. (2015). Causal Mediation Analysis: Warning! Assumptions Ahead. American Journal of Evaluation. doi: 10.1177/1098214015594689

Kervyn, N., Yzerbyt, V., \& Judd, C. M. (2010). Compensation between warmth and competence: Antecedents and consequences of a negative relation between the two fundamental dimensions of social perception. European Review of Social Psychology, 21(1), 155-187. doi: 10.1080/13546805.2010.517997

Kinder, D. R., Peters, M. D., Abelson, R. P., \& Fiske, S. T. (1980). Presidential Prototypes. Political Behavior, 2(4), 315-337. doi: 10.2307/586418

Koch, T., \& Obermaier, M. (2014). With Heart and (No) Mind? How Recipients Negatively Infer Missing Information About Politicians and How This Affects the Assessment of the Speaker. Communication Research. doi: 10.1177/0093650214565005

Kuklinski, J. H., Quirk, P. J., Jerit, J., Schwieder, D., \& Rich, R. F. (2000). Misinformation and the Currency of Democratic Citizenship. Journal of Politics, 62(3), 790-816. doi: $10.1111 / 0022-3816.00033$

Lau, R. R., \& Redlawsk, D. P. (2001). Advantages and disadvantages of cognitive heuristics in political decision making. American Journal of Political Science, 45(4), 951-971.

Lau, R. R., \& Redlawsk, D. P. (2006). How Voters Decide: Cambridge University Press. 
Lawrence, E. D., \& Sides, J. (2014). The consequences of political innumeracy. Research \& Politics, 1(2). doi: 10.1177/2053168014545414

Miller, A. H., Wattenberg, M. P., \& Malanchuk, O. (1986). Schematic Assessments of Presidential Candidates. American Political Science Review, 80(02), 521-540. doi: doi:10.2307/1958272

Montgomery, J. M., Nyhan, B., \& Torres, M. (2016). How conditioning on post-treatment variables can ruin your experiment and what to do about it. Annual meeting of the Midwest Political Science Association, Chicago, IL, April 2016.

Nadeau, R., Niemi, R. G., \& Levine, J. (1993). Innumeracy About Minority Populations. Public Opinion Quarterly, 57(3), 332-347. doi: 10.1086/269379

Ohr, D., \& Oscarsson, H. (2013). Leader Traits, Leader Image and Vote Choice. In K. Arts, A. Blais \& H. Schmitt (Eds.), Political Leaders and Democratic Elections. Oxford: Oxford University Press.

Pedersen, R. T. (2016). Ratio Bias and Policy Preferences: How Equivalency Framing of Numbers Can Affect Attitudes. Political Psychology (early view). doi: 10.1111/pops. 12362

Popkin, S. L. (1991). The Reasoning Voter: Communication and Persuasion in Presidential Elections. Chicago: University of Chicago Press.

Porter, T. m. (1986). The Rise of Statistical Thinking 1820-1900. Princeton, NJ: Princeton University Press.

Prévost, J.-G., \& Beaud, J.-P. (2012). Statistics, Public Debate and the State, 1800-1945: Pickering \& Chatto.

Schneider, M. C., \& Bos, A. L. (2014). Measuring Stereotypes of Female Politicians. Political Psychology, 35(2), 245-266. doi: 10.1111/pops.12040 
Schueler, B. E., \& West, M. R. (2015). Sticker Shock: How Information Affects Citizen Support for Public School Funding. Public Opinion Quarterly.

Sigelman, L., \& Niemi, R. G. (2001). Innumeracy about Minority Populations. Public Opinion Quarterly, 65(1), 86-94.

Sniderman, P. M., \& Theriault, S. M. (2004). The Structure of Political Argument and the Logic of Issue Framing. In W. E. Saris \& P. M. Sniderman (Eds.), (pp. 133-165). Princeton: Princeton University Press.

Tingley, D., Yamamoto, T., Hirose, K., Keele, L., \& Imai, K. (2014). mediation: R package for causal mediation analysis. Journal of Statistical Software, 59(5), 1-38. doi: 10.18637/jss.v059.i05

Utych, S. M., \& Kam, C. D. (2014). Viability, Information Seeking, and Vote Choice. The Journal of Politics, 76(01), 152-166. doi:10.1017/S0022381613001126

Wong, C. J. (2007). "Little” and "Big” Pictures in Our Heads: Race, Local Context, and Innumeracy About Racial Groups in the United States. Public Opinion Quarterly, 71(3), 392-412. doi: 10.1093/poq/nfm023

Zhang, Y. C., \& Schwarz, N. (2013). The power of precise numbers: A conversational logic analysis. Journal of Experimental Social Psychology, 49(5), 944-946. doi: http://dx.doi.org/10.1016/j.jesp.2013.04.002 


\section{Appendix: Models, Tables and Additional Figures}

Table 1: Effects on competence

\begin{tabular}{lccc}
\hline & $\begin{array}{c}(1) \\
\text { Competence of } \\
\text { Pro }\end{array}$ & $\begin{array}{c}\text { Competence of } \\
\text { Con }\end{array}$ & $\begin{array}{c}(3) \\
\text { Competence } \\
\text { differential }\end{array}$ \\
\hline Condition 1: No numbers & ref. cat. & ref. cat. & ref. cat. \\
Condition 2: Pro using numbers & $0.05^{*}$ & $-0.04^{*}$ & $0.09^{* *}$ \\
& $(0.02)$ & $(0.02)$ & $(0.03)$ \\
Condition 3: Con using numbers & -0.01 & $0.06^{* *}$ & $-0.07^{*}$ \\
& $(0.02)$ & $(0.02)$ & $(0.03)$ \\
Condition 4: Both using & -0.01 & 0.03 & -0.03 \\
numbers & $(0.02)$ & $(0.02)$ & $(0.03)$ \\
& & & \\
Constant & $0.56^{* *}$ & $0.55^{* *}$ & 0.01 \\
& $(0.01)$ & $(0.01)$ & $(0.02)$ \\
\hline$N$ & 923 & 923 & 923 \\
$R^{2}$ & 0.012 & 0.031 & 0.034 \\
\hline$N$
\end{tabular}

Notes: OLS regression coefficients (and standard errors)

${ }^{*} p<0.05,{ }^{* *} p<0.01$ 


\begin{tabular}{lccc}
\hline & $\begin{array}{c}(4) \\
\text { Warmth of } \\
\text { Pro }\end{array}$ & $\begin{array}{c}(5) \\
\text { Warmth of } \\
\text { Con }\end{array}$ & $\begin{array}{c}(6) \\
\text { Warmth } \\
\text { differential }\end{array}$ \\
\hline Condition 1: No numbers & ref. cat. & ref. cat. & ref. cat. \\
Condition 2: Pro using numbers & 0.02 & -0.01 & 0.03 \\
& $(0.02)$ & $(0.02)$ & $(0.03)$ \\
Condition 3: Con using numbers & $0.04^{*}$ & -0.01 & 0.05 \\
& $(0.02)$ & $(0.02)$ & $(0.03)$ \\
Condition 4: Both using & 0.03 & -0.01 & 0.04 \\
numbers & $(0.02)$ & $(0.02)$ & $(0.03)$ \\
& & & \\
Constant & $0.53^{* *}$ & $0.58^{* *}$ & $-0.06^{* *}$ \\
& $(0.01)$ & $(0.01)$ & $(0.02)$ \\
\hline$N$ & 923 & 923 & 923 \\
$R^{2}$ & 0.005 & 0.001 & 0.004 \\
\hline$N$
\end{tabular}

Notes: OLS regression coefficients (and standard errors)

${ }^{*} p<0.05,{ }^{* *} p<0.01$

Table 3: Effects on persuasion

\begin{tabular}{lc}
\hline & $(7)$ \\
& GM attitude \\
\hline Condition 1: No numbers & ref. cat. \\
Condition 2: Pro using numbers & 0.01 \\
& $(0.04)$ \\
Condition 3: Con using numbers & 0.01 \\
& $(0.04)$ \\
Condition 4: Both using numbers & 0.02 \\
& $(0.04)$ \\
Constant & $-0.22^{* *}$ \\
& $(0.03)$ \\
\hline$N$ & 923 \\
$R^{2}$ & 0.000 \\
\hline Notes: OLS regression coefficients (and standard errors) \\
${ }^{*} p<0.05,{ }^{* *} p<0.01$
\end{tabular}




\begin{tabular}{lcc}
\hline & $(8)$ & $(9)$ \\
& Voting for Pro & Voting for Pro \\
& OLS & ORDERED LOGISTIC \\
Condition 1: No numbers & ref. cat. & ref. cat. \\
Condition 2: Pro using numbers & $0.05^{*}$ & $0.40^{*}$ \\
& $(0.03)$ & $(0.20)$ \\
Condition 3: Con using numbers & -0.01 & -0.12 \\
& $(0.03)$ & $(0.20)$ \\
Condition 4: Both using numbers & -0.01 & -0.08 \\
& $(0.03)$ & $(0.19)$ \\
Constant & $0.46^{* *}$ & - \\
& $(0.02)$ & $-1.69^{* *}$ \\
Cut 1 & - & $(0.16)$ \\
& & 0.28 \\
$\mathrm{R}^{2} /$ pseudo $R^{2}$ & & $(0.14)$ \\
\hline
\end{tabular}

Notes: Regression coefficients (and standard errors)

${ }^{*} p<0.05,{ }^{* *} p<0.01$

The 231 respondents answering "don't know" when asked about vote choice were excluded from the ordered logistic regression in model 9. 
Table 5: Regressions Used for Mediation Analyses

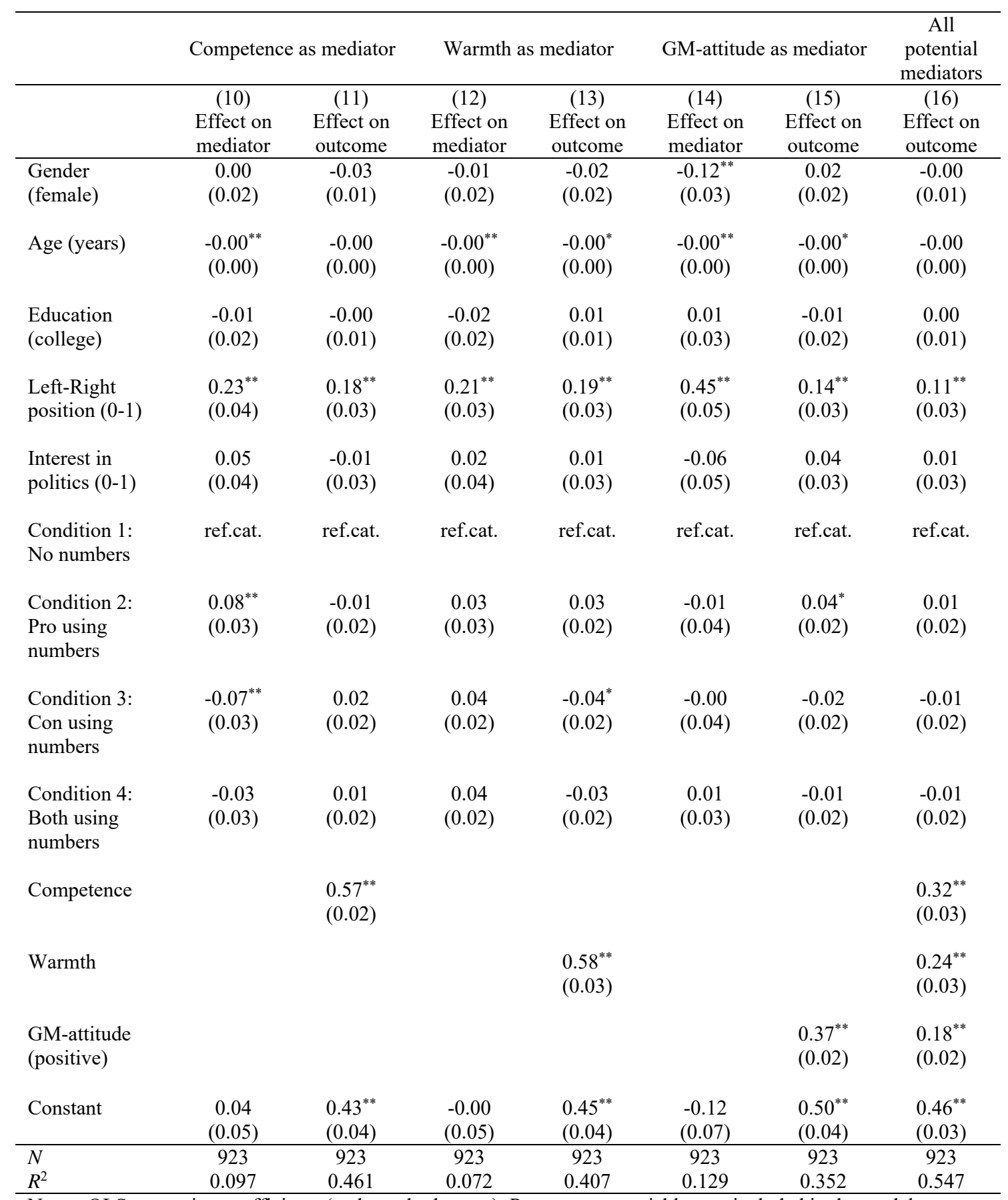

Notes: OLS regression coefficients (and standard errors). Pretreatment variables are included in the models to make the sequential ignorability assumption as plausible as the data permit (Imai \& Yamamoto 2013).

${ }^{*} p<0.05,{ }^{* *} p<0.01$ 
Table 6: Mediation by Competence, Warmth and GM-attitude

\begin{tabular}{llccc}
\hline & & Competence & Warmth & GM-attitude \\
\hline \multirow{4}{*}{ Comparing Conditions 1 and 2 } & ACME & $0.04^{* *}$ & 0.01 & -0.00 \\
& ADE & -0.01 & 0.03 & 0.04 \\
& Total Effect & 0.04 & 0.04 & 0.04 \\
\hline \multirow{3}{*}{ Comparing Conditions 1 and 3 } & ACME & $-0.04^{* *}$ & 0.02 & -0.00 \\
& ADE & 0.02 & -0.04 & -0.02 \\
& Total Effect & -0.02 & -0.02 & -0.02 \\
\hline \multirow{4}{*}{ Comparing Conditions 1 and 4 } & ACME & -0.02 & 0.02 & 0.00 \\
& ADE & 0.01 & -0.03 & -0.01 \\
& Total Effect & 0.01 & -0.01 & -0.01 \\
\hline \multirow{4}{*}{ Comparing Conditions 2 and 3 3 ACME } & $0.09^{* *}$ & -0.01 & -0.00 \\
& ADE & -0.03 & $0.07^{* *}$ & $0.06^{* *}$ \\
& Total Effect & $0.06^{*}$ & $0.06^{*}$ & $0.06^{*}$ \\
\hline \multirow{3}{*}{ Comparing Conditions 3 and 4 } & ACME & $0.06^{* *}$ & -0.01 & -0.00 \\
& ADE & -0.01 & $0.06^{* *}$ & $0.06^{* *}$ \\
& Total Effect & $0.05^{*}$ & $0.05^{*}$ & $0.05^{*}$ \\
\hline & ACME & -0.02 & 0.00 & -0.00 \\
& Total Effect & -0.01 & -0.01 & -0.00 \\
\hline
\end{tabular}

Notes: Effect calculated using R Package "Mediation" (Tingley et al., 2014; Imai et al., 2010b). All estimations based on 1,000 simulations.

ACME: Average Causal Mediation Effect

ADE: Average Direct Effect

${ }^{*} p<0.05,{ }^{* *} p<0.01$ 
Table 7: Regressions Used for Moderation Analyses

\begin{tabular}{|c|c|c|}
\hline & $\begin{array}{c}\text { (17) } \\
\text { Effect on mediator }\end{array}$ & $\begin{array}{c}\text { (18) } \\
\text { Effect on outcome }\end{array}$ \\
\hline Gender (female) & $\begin{array}{c}0.02 \\
(0.02)\end{array}$ & $\begin{array}{l}-0.03 \\
(0.01)\end{array}$ \\
\hline Age (years) & $\begin{array}{c}-0.00^{* *} \\
(0.00)\end{array}$ & $\begin{array}{l}-0.00 \\
(0.00)\end{array}$ \\
\hline Education (college) & $\begin{array}{l}-0.00 \\
(0.02)\end{array}$ & $\begin{array}{c}0.00 \\
(0.01)\end{array}$ \\
\hline Left-Right position (0-1) & $\begin{array}{l}0.17^{* *} \\
(0.04)\end{array}$ & $\begin{array}{l}0.17^{* *} \\
(0.03)\end{array}$ \\
\hline Interest in politics $(0-1)$ & $\begin{array}{l}0.09^{*} \\
(0.04)\end{array}$ & $\begin{array}{l}-0.00 \\
(0.03)\end{array}$ \\
\hline Condition 1: No numbers & ref.cat. & ref.cat. \\
\hline Condition 2: Pro using numbers & $\begin{array}{l}0.08^{*} \\
(0.04)\end{array}$ & $\begin{array}{c}0.01 \\
(0.03)\end{array}$ \\
\hline Condition 3: Con using numbers & $\begin{array}{l}-0.08^{*} \\
(0.04)\end{array}$ & $\begin{array}{c}0.05 \\
(0.03)\end{array}$ \\
\hline Condition 4: Both using numbers & $\begin{array}{l}-0.04 \\
(0.04)\end{array}$ & $\begin{array}{c}0.04 \\
(0.03)\end{array}$ \\
\hline GM-attitude (folded scale) & $\begin{array}{l}-0.29^{* *} \\
(0.06)\end{array}$ & $\begin{array}{l}-0.04 \\
(0.04)\end{array}$ \\
\hline Condition 1: No numbers $\times$ GM-attitude (folded scale) & ref.cat. & ref.cat. \\
\hline Condition 2: Pro using numbers $\times$ GM-attitude (folded scale) & $\begin{array}{l}-0.00 \\
(0.08)\end{array}$ & $\begin{array}{l}-0.05 \\
(0.06)\end{array}$ \\
\hline $\begin{array}{l}\text { Condition 3: Con using numbers } \times \text { GM-attitude (folded } \\
\text { scale) }\end{array}$ & $\begin{array}{c}0.02 \\
(0.08)\end{array}$ & $\begin{array}{l}-0.10 \\
(0.06)\end{array}$ \\
\hline $\begin{array}{l}\text { Condition 4: Both using numbers } \times \text { GM-attitude (folded } \\
\text { scale) }\end{array}$ & $\begin{array}{r}0.03 \\
(0.08)\end{array}$ & $\begin{array}{l}-0.09 \\
(0.06)\end{array}$ \\
\hline Competence & & $\begin{array}{l}0.66^{* *} \\
(0.04)\end{array}$ \\
\hline Competence $\times$ GM-attitude (folded scale) & & $\begin{array}{c}-0.25^{* *} \\
(0.06)\end{array}$ \\
\hline Constant & $\begin{array}{c}0.10^{*} \\
(0.05) \\
\end{array}$ & $\begin{array}{l}0.43^{* *} \\
(0.04) \\
\end{array}$ \\
\hline $\begin{array}{l}N \\
R^{2}\end{array}$ & $\begin{array}{c}923 \\
0.175\end{array}$ & $\begin{array}{c}923 \\
0.481\end{array}$ \\
\hline
\end{tabular}

Notes: OLS regression coefficients (and standard errors). Pretreatment variables are included in the models to make the sequential ignorability assumption as plausible as the data permit (Imai \& Yamamoto 2013)

${ }^{*} p<0.05,{ }^{* *} p<0.01$ 
Figure 5: Estimates of ACME, ADE and Total Effect (With 95\% CIs)

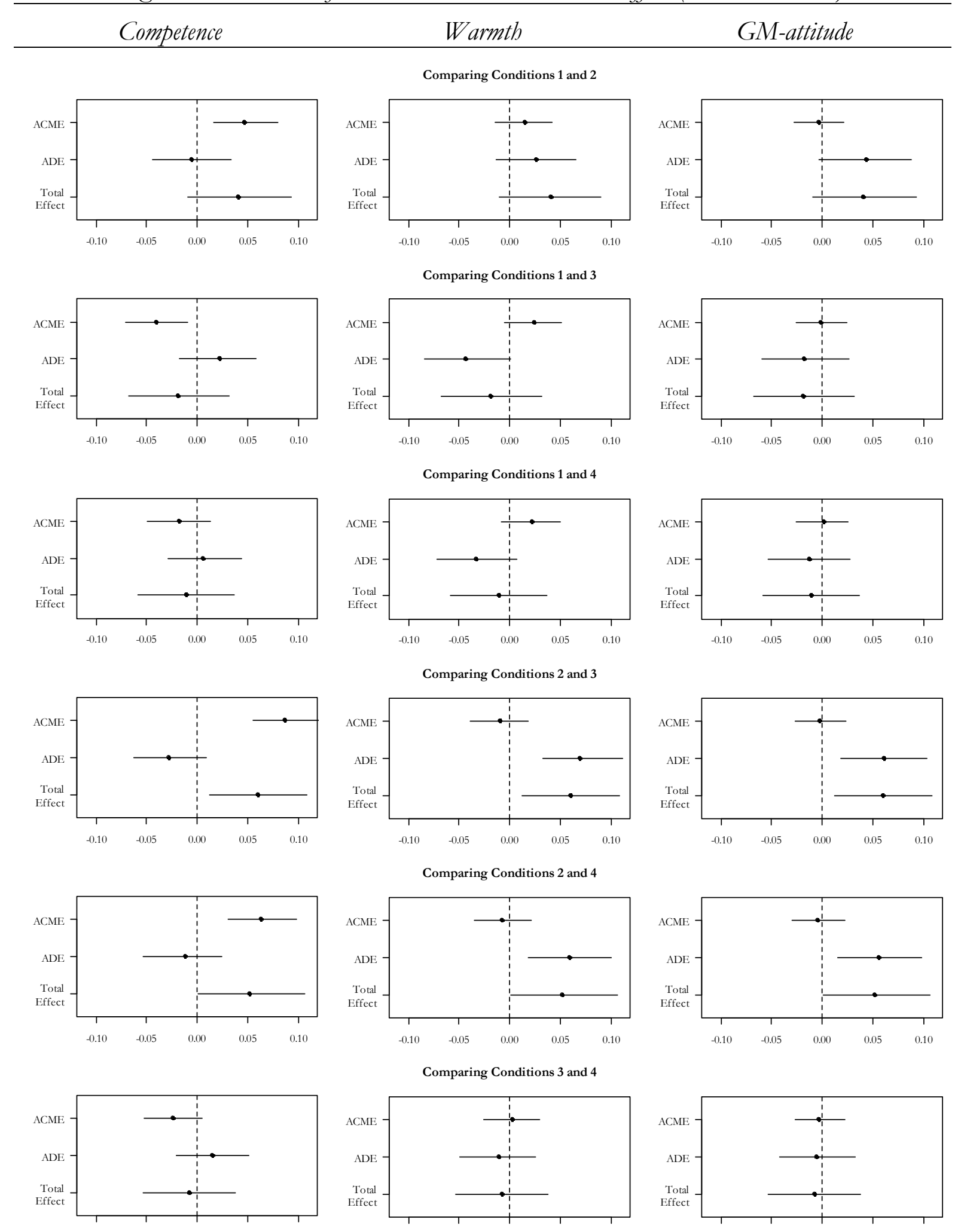

Note: Figure is based on results in table 6.

ACME: Average Causal Mediation Effect

ADE: Average Direct Effect 
Figure 6: Sensitivity Analyses, Mediation by Competence

These figures illustrate the ACMEs of competence, contingent on the conditions compared and the sensitivity parameter, $\rho$ (with $95 \% \mathrm{CIs}$ ). For all comparisons where the ACMEs are significant, they remain significant until $p$ reaches $.58-60$ (Figures for the ACMEs of warmth and GM-attitudes are omitted. They are insignificant for all conditions and values of $\rho$ ).

Comparing Conditions 1 and 2

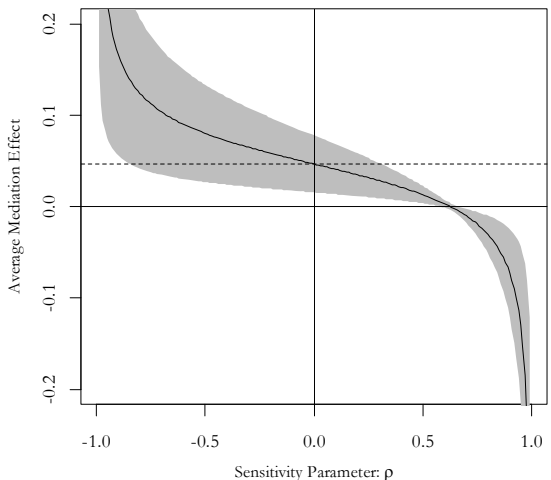

Comparing Conditions 1 and 4

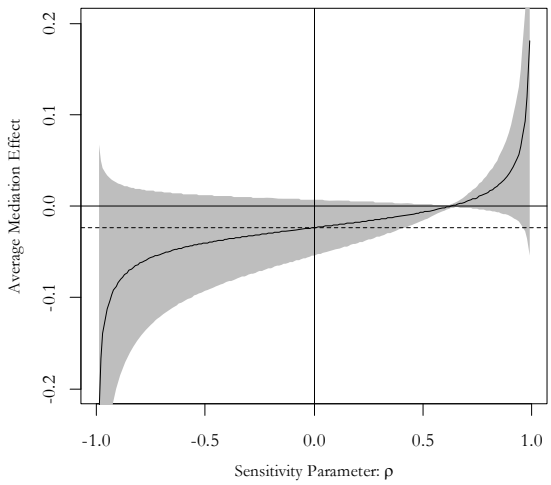

Comparing Conditions 2 and 4

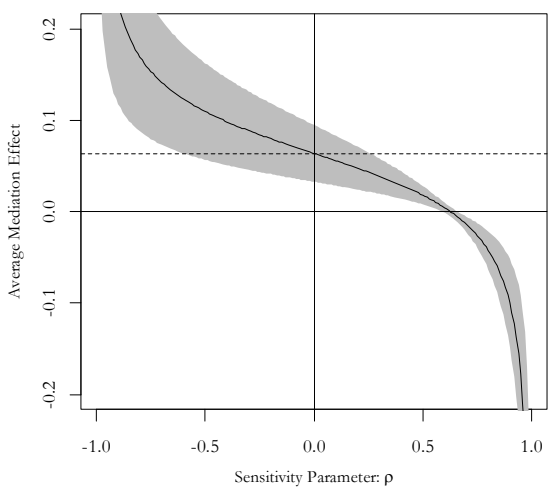

Comparing Conditions 1 and 3

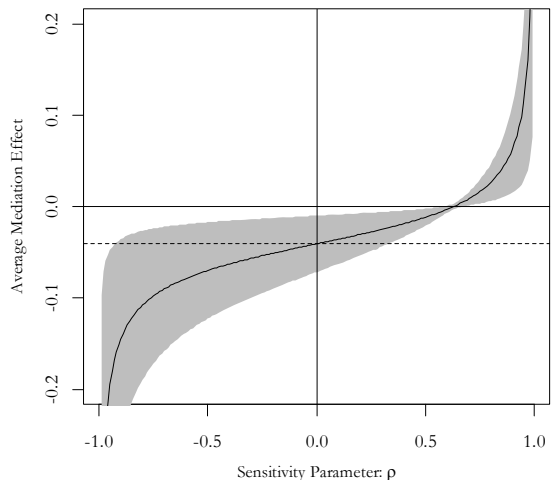

Comparing Conditions 2 and 3

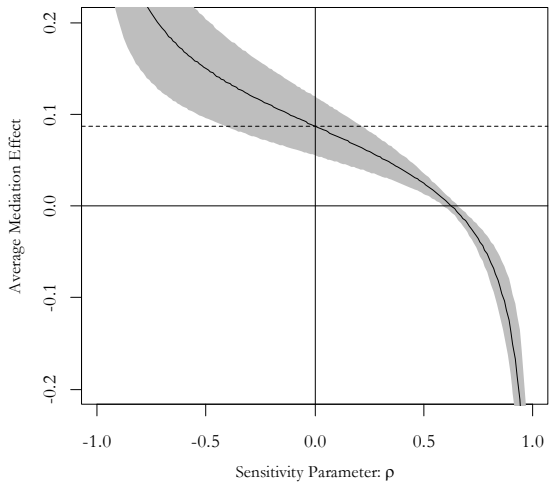

Comparing Conditions 3 and 4

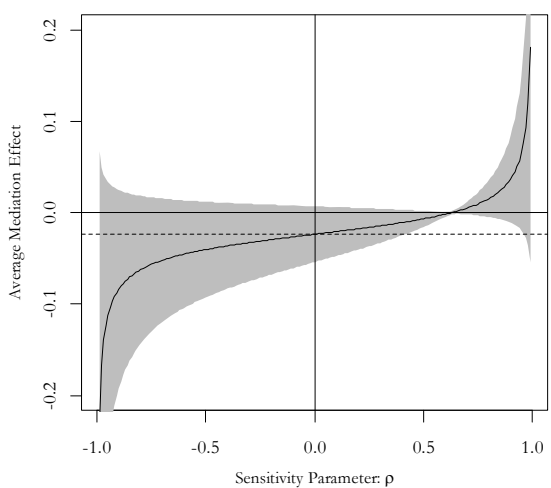

Note: Sensitivity estimates calculated using R Package "Mediation" (Tingley et al., 2014; Imai et al., 2010b). All estimations based on 1,000 simulations. 